\title{
Do stock options overcome managerial risk aversion? Evidence from exercises of executive stock options
}

\author{
Randall A. Heron \\ Kelley School of Business \\ Indiana University \\ Indianapolis, IN 46202 \\ Tel: 317-274-4984 \\ Email: rheron@iupui.edu \\ Erik Lie \\ Henry B. Tippie College of Business \\ University of Iowa \\ Iowa City, IA 52242 \\ Tel: 319-335-0846 \\ Email: erik-lie@uiowa.edu \\ Management Science, forthcoming
}

\begin{abstract}
$\underline{\text { Abstract }}$
We report that the probability that executives exercise options early decreases with the volatility of the underlying stock return. We interpret this to mean that executives' subjective option value increases with volatility and that option grants increase executives' risk appetite. Further decomposition reveals that the results are most pronounced for idiosyncratic volatility, consistent with our conjecture that executives believe they can better predict or influence the resolution of idiosyncratic uncertainty than systematic uncertainty, and, thus, favor the former.
\end{abstract}

We thank the Editor (Wei Jiang), the Associate Editor, two anonymous referees, and seminar participants at BI Norwegian Business School, Cal State Fullerton, City University of Hong Kong, Florida State University, Northeastern University, the University of Nebraska, and the University of Oregon for helpful comments.

This is the author's manuscript of the article published in final edited form as:

Heron, R. A., \& Lie, E. (2016). Do Stock Options Overcome Managerial Risk Aversion? Evidence from Exercises of Executive Stock Options. Management Science. http://dx.doi.org/10.1287/mnsc.2016.2485 


\title{
Do stock options overcome managerial risk aversion? Evidence from exercises of executive stock options (ESOs)
}

\begin{abstract}
$\underline{\text { Abstract }}$
We report that the probability that executives exercise options early decreases with the volatility of the underlying stock return. We interpret this to mean that executives' subjective option value increases with volatility and that option grants increase executives' risk appetite. Further decomposition reveals that the results are most pronounced for idiosyncratic volatility, consistent with our conjecture that executives believe they can better predict or influence the resolution of idiosyncratic uncertainty than systematic uncertainty, and, thus, favor the former.
\end{abstract}




\section{Introduction}

Jensen and Meckling (1976) describe how the interests of executives and shareholders diverge when executives maximize their own utility rather than shareholders' wealth. Without proper incentives, executives generally prefer to consume perquisites and undertake less risk than what optimizes firm value. Jensen and Meckling suggest that one solution to reduce the divergence of interests is "to establish incentive compensation systems for the manager or to give him stock options which in effect give him a claim on the upper tail of the outcome distribution” (p. 353). Other studies, including Smith and Stulz (1985) and Guay (1999), support the view that option-based compensation mitigates managerial risk aversion and induces greater risk-taking behavior. The underpinning for these studies is that the objective option value, e.g., the Black-Scholes value, is a convex function of the stock value, and therefore increases with stock price volatility.

However, two factors complicate the application of objective value functions for executive stock options (ESOs). First, ESOs are not easily transferable, i.e., executives cannot sell ESOs nor fully hedge their exposure without violating company policies. Second, executives are inherently undiversified, with disproportionate financial and human capital invested in the company. On this backdrop, Lambert, Larcker, and Verrechia (1991), Carpenter (2000), Hall and Murphy (2002), and Ross (2004) show that risk-averse executives place a lower value on their ESOs than do diversified investors and that the concavity of executives' utility functions could eclipse the convexity of the option payoffs, in which case ESOs would encourage less risk-taking behavior.

Bettis, Bizjak, and Lemmon (2005) explore ESO values and incentives further, with a particular emphasis on the role of exercises. In their utility-based valuation model (which is an extension of Carpenter, 1998), executives exercise if the stock price reaches a "threshold price,” such that the utility from locking in the gain exceeds the utility from holding the option. Bettis, Bizjak, and Lemmon estimate that an increase in the stock price volatility from the base-case parameterization of $39 \%$ to $58 \%$ is associated with a higher stock price upon exercise and a higher subjective valuation. Thus, it appears that higher volatility raises the threshold price, as executives place greater value on holding the options. They further 
calibrate their model to a sample of option grants in the Execucomp database between 1992 and 2002, and report that the average subjective convexity is positive.

Overall, the theoretical studies provide equivocal predictions on the effect of ESOs on executives’ risk appetite. Past empirical studies provide evidence using two different testing frameworks, and, thus, we place the studies in two different camps. The first camp, to which our study belongs, examines the effect of stock return volatility on the timing of ESO exercises. If risk enhances executives’ subjective ESO valuation (meaning that ESOs increase risk appetite), higher risk should discourage executives from early exercise. Consistent with this view, Carpenter, Stanton, and Wallace (2013) report that employees retain their options when volatility is high, with the caveat that the employees in their sample include nonexecutives, while Izhakian and Yermack (2014) find that executives retain options in the presence of high volatility. In addition, Huddart and Lang (1996) document evidence, albeit statistically weak, that the top five percent level employees retain options when volatility is high. Conversely, Hemmer, Matsunaga, and Shevlin (1996), Bettis, Bizjak, and Lemmon (2005), and Klein and Maug (2011) find that executives are more likely to exercise their options early in the presence of high volatility. ${ }^{1}$ However, unlike the former three studies, these latter three studies compare early exercises to late exercises, which makes their results susceptible to secular trends. As an example, stock prices are often described as a stochastic process with a positive drift. It follows that, all else equal, later exercises will be associated with higher moneyness than early exercises, yielding the potentially misleading inference that executives are more likely to exercise options early when they are less in-the-money. Another possibility is that stock price volatility naturally declines as firms mature, such that early exercises are associated with higher volatility. Indeed, in our sample, both total and idiosyncratic volatility tends to decline from the year of the option grants through the maturity year.

\footnotetext{
${ }^{1}$ In a robustness test, Klein and Maug (2011) report that executives are more likely to retain options when idiosyncratic volatility is high, and Fos and Jiang (2015) report the same in their study of how proxy contests affect exercise behavior.
} 
The second empirical camp leaps the question of whether ESOs increase risk appetite to the question of whether ESOs lead to greater risk-taking. Numerous studies report that ESOs (often measured by their objective convexity) lead to riskier corporate policies, including riskier investments (Agrawal and Mandelker, 1987; Coles, Daniel, and Naveen, 2006; Gormley, Matsa, and Milbourn, 2013), less hedging (Tufano, 1996; Rajgopal and Shevlin, 2002; Knopf, Nam, and Thornton, 2002), higher leverage (Berger, Ofek, and Yermack, 1997; Coles, Daniel, and Naveen, 2006; Chava and Purnanandam, 2010; Gormley, Matsa, and Milbourn, 2013; Shue and Townsend, 2013), and less cash (Chava and Purnanandam, 2010; Gormley, Matsa, and Milbourn, 2013). Moreover, DeFusco, Johnson, and Zorn (1990), Guay (1999), Cohen, Hall, and Viceira (2000), Rajgopal and Shevlin (2002), Low (2009), Gormley, Matsa, and Milbourn (2013), and Shue and Townsend (2013) report evidence that ESOs inflate cash flow volatility and/or stock return volatility. In contrast, Liu and Mauer (2011), Hayes, Lemmon, and Qiu (2012), and Kini and Williams (2012) report evidence that ESOs inflate cash holdings and reduce leverage and stock return volatility. Bettis, Bizjak, Coles, and Kalpathy (2010) and Bizjak, Bettis, Coles, and Kalpathy (2015) caution that performance-vesting provisions, which have become more common in recent years, complicate the convexity estimations in many of these studies. Furthermore, it is widely recognized that endogeneity clouds the interpretation of some results, so we are wary of making a firm conclusion based on the results in this literature.

We revisit the effect of stock option volatility on option exercises among executives using a sample constructed to subdue some of the data limitations inherent in many past studies of option exercises. ${ }^{2}$ In particular, we follow a large set of option grants made between 1994 and 2001 that have reached their expiration dates as of the time of our analysis and focus on "regular" exercises (i.e., exercises not associated with the disappearance of the firm resulting from, e.g., takeovers or mergers) that we can fully reconcile

\footnotetext{
${ }^{2}$ Unless we specify otherwise, we refer to all individuals who have to file securities holdings and transactions according to Section 16 of the Securities and Exchange Act of 1934 as executives. But we also examine non-executive directors separately.
} 
with the original grants. The advantage of this approach is that we get valuable information about the options from the original grant filings (including the total number of options granted, years to maturity, and vesting dates) and can track what happens to the options over time. Also, our approach allows us to compare the decision to exercise options to contemporaneous decisions not to exercise options, rather than to later decisions to exercise options. Thus, we mitigate the concern caused by systematic time-trends in the covariates.

We find that high volatility discourages executives from exercising their options. We also show that the difference in results in our study versus those in earlier studies is primarily attributable to our methodology of comparing early exercises to non-exercises rather than to late exercises. We interpret our results as evidence that executives place a higher value on ESOs when volatility is high. Thus, to the extent that the executives are inherently risk averse, the convexity of the option payoff overcomes the concavity of their utility functions.

We further examine the differential effects of idiosyncratic volatility and systematic volatility. Armstrong and Vashishtha (2012) argue that executives with options favor exposure to systematic volatility, because systematic volatility inflates the value of the option positions and can be hedged if the executives are risk averse. We propose an alternative and novel conjecture that executives believe they can better predict or influence the resolution of idiosyncratic uncertainty, and, thus, favor idiosyncratic volatility to systematic volatility when they have options. Analogously, the insider trading literature (e.g., Lakonishok and Lee, 2001) presumes that insiders have superior information about firm-specific prospects that is useful for predicting future stock returns. Furthermore, Pan, Wang, and Weisbach (2015) posit and present evidence that the idiosyncratic stock return partially reflects the market's uncertainty about executives' ability and strategic vision (and, we contend, effort). Executives arguably have more information about their own ability and strategy and can choose their effort level. On this basis, they have more control of the resolution of the idiosyncratic uncertainty. Our alternative conjecture should be more prominent among executives than among non-executive directors, because executives are likely to possess superior information about executives' ability and strategy and have a more direct influence on the 
operations of the company (Harris and Raviv, 2008), and, hence, can better predict or influence the resolution of idiosyncratic uncertainty. Consistent with our conjecture (but inconsistent with the argument of Armstrong and Vashishtha, 2012), we show that executives are more likely to retain options when the idiosyncratic volatility is high than if the systematic volatility is high. In addition, we show that nonexecutive directors also retain options when faced with volatility, but show no preference for this volatility to be idiosyncratic.

Our results contribute most directly to the literature on option exercises among executives, primarily by showing that high volatility, and in particular idiosyncratic volatility, discourages exercise. Furthermore, we contribute to the literature seeking to value ESOs from the perspective of executives, in that our results imply that executives' valuation of ESOs increases with volatility, especially idiosyncratic volatility. A further implication is that, if executives believe they can better predict or influence the resolution of idiosyncratic risk, they place a higher value on ESOs than extant utility-based models suggest. Finally, our results speak to the fundamental question of whether option grants incentivize executives to take on additional risk. Our exercise results suggest that ESOs provide executives with an incentive to inflate risk, especially idiosyncratic risk. However, our study is not designed to offer evidence on whether executives act on that incentive to inflate risk, and we leave that to other studies.

\section{Sample and methodology}

\subsection{Sample}

We obtain our sample of stock option grants, exercises, option holdings, and direct and indirect stock holdings from the Thomson Financial Insider Filing database, which captures insider transactions reported on SEC forms 3, 4, 5, and 144. Our sample of grants and exercises covers the period from 1994 to 2011. We focus our sample on 10-year grants that are at-the-money on the grant date, because (i) this 
facilitates a large, yet homogenous sample of grants, and (ii) the vast majority of observations with erroneous grant dates, maturity dates, or exercise prices naturally drop out as a result. ${ }^{3}$

We further require that we can fully reconcile the grants with corresponding exercises. In particular, for each person and family of grants (where a grant family is defined as all grants for a person with the same exercise price and maturity, but not necessarily the same vesting date), we identify all exercises during the life of the options with the same maturity, and compare the product of the options and exercise price in the grant family with the analogous product for the exercises. ${ }^{4}$ If these two products are within one percent of each other, we consider the grants and exercises to be reconciled.

Our past experience working with the SEC filings that make up the database has revealed that that filings are commonly erroneous, incomplete, or perhaps even missing. ${ }^{5}$ Our reconciliation procedure

${ }^{3}$ To gauge whether a grant was at-the-money on the grant date, we compared the provided exercise price to the closing prices on the provided grant date and the day before, because it is common practice to use either the closing price on the grant date or the day before as the exercise price. If the exercise price is within two percent of one of these closing prices (after accounting for stock dividends and splits between the grant and filing dates), we deem the grant to be at-the-money.

${ }^{4}$ We use the product of the number of options and the exercise price instead of just the number of options, because this effectively deals with any stock splits. An exception that we would not be able to track would be options that were repriced, especially if variable repricing had taken place. Incidentally, Kalpathy (2009) identifies 112 repricings of option grants to CEOs of S\&P 1500 firms between 1995 and 2003. Assuming that the 112 repricings occur in different firm-years, they represent a little less than one percent of the 13,500 firm-years in his sample.

${ }^{5}$ The SEC unveiled electronic filing of corporate insider trades on May 5, 2003 and required electronic filing beginning on June 30, 2003, which undoubtedly led to a reduction in filing errors and also transcription / tabulation errors in the TFN database. We are unaware of a criteria used by the SEC to reprimand erroneous, missing, or late filings outside of placing an Item 405 disclosure in the company's 
mitigates these issues significantly. First, we are likely to weed out lots of filings with errors. The errors often appear to be the result of lack of care when filling out the forms, and can be as simple as switching the vesting and maturity dates or filling in one digit of a date incorrectly. But even seemingly innocuous errors can affect the variables significantly. Second, we do not have to use the exercise prices from the filings to estimate moneyness upon exercise. While these prices might not be outright wrong, the adjustments for splits (which are common leading up to exercises) vary, which in turn could introduce bias in the moneyness estimates. Because we only include options that are granted-at-the money, we simply use the pair of split-adjusted market prices on the grant and exercise dates to estimate moneyness upon exercise. Third, we can retain exercise filings with incomplete information about vesting dates in our sample. Vesting dates in exercises are often excluded when the options vest in installments. In our procedure, we simply assume that the vesting date of the exercised options is the earliest of the vesting dates of the options in a grant family that have not yet been exercised. ${ }^{6}$

One could argue that a disadvantage of our procedure is that we do not include grants of options that were never exercised, and therefore cannot estimate the fraction of options that were exercised during the life of the options or use these grants as a control sample. However, the problem of missing exercise filings (in many cases because the individuals discontinue their status as Section 16 employees, such that they are no longer required to file their transactions) along with various errors and option repricings would

proxy statement and 10-K denoting a late Section 16 filing. Obviously, after the discovery of option grant and exercise backdating, the SEC focused greater attention on the common problem of late filings.

${ }^{6}$ For example, suppose a grant family of 1,000 options on 1/1/2000 vested in equal installments on $1 / 1 / 2001,1 / 1 / 2002,1 / 1 / 2003$, and 1/1/2004, and that 200 options were exercised on $6 / 1 / 2001$, 300 were exercised on 8/1/2002, and 500 were exercised on 12/1/2004. We would then assume that the first 200 options exercised all had a vesting date of 1/1/2001, along with 50 of the 300 options exercised later. We would further assume that the remaining 250 of the 300 options had a vesting date of $1 / 1 / 2002$, and that the last 500 options exercised had vesting dates of 1/1/2003 and 1/1/2004 in equal portions. 
cause any effort to estimate the fraction of options granted that were ultimately exercised to be biased downward. Furthermore, we do not believe such options should be used as a control sample of unexercised options if we cannot reasonably determine whether they were actually exercised.

While our unique sample criteria significantly narrow down the sample, we have the benefit of an exceptionally clean sample for a large cross-section of firms and individuals. Moreover, our sample should not suffer from any biases, unless individuals who make repeated filing errors (and, thus, are excluded from our sample) somehow exercise their options in manners that differ significantly from that of the population as a whole.

After identifying grants and exercises we can reconcile, we remove exercises that occur within 20 trading days of merger completion dates, or have exercise codes other than $\mathrm{M}$ or $\mathrm{X}$ (which signify in-themoney or at-the-money options). These other exercise codes include dispositions to the issuer of issuer equity securities pursuant to Rule 16b-3(e), dispositions pursuant to a tender of shares in change of control transactions, and cancellations. Of these, $66 \%$ occur within twenty trading days of a merger completion date, whereas the corresponding fraction is less than $4 \%$ for exercises denoted as other than $\mathrm{M}$ or $\mathrm{X}$. We also remove other exercises where our estimates suggest that the options were not in-the-money.

Figure 1 depicts the distributions of the grants and exercises across their respective time periods. As a result of our sample identification, the options grants are from 1994-2001 and the exercises are from 1994-2011. There is a clear upward trend in the number of grants in our sample between 1994 and 2001, reflecting the increasing tendency for companies to use options as part of executive compensation during this period. The number of exercises increases gradually through 2004, as more of the options in the sample vest, and then declines in the subsequent years, especially during the financial crisis when many of the options fall underwater.

We partition the sample of more than 35,000 exercises on the basis of whether the shares acquired upon the exercise were immediately sold, defined as sold the same day as the options were exercised. We focus on the results for the subsample of exercises with immediate sales (representing more than three quarters of all exercises in the sample) for three reasons. First, the theoretical models in the exercise 
literature implicitly assume that acquired shares are sold right after exercises of options. Second, the smaller sub-sample of exercise-and-hold transactions are often driven by factors outside the scope of our study, e.g., tax motives (Cicero, 2009) and value of votes (Fos and Jiang, 2015). Third, the exercise-and-hold transactions might have been backdated (Cicero, 2009), in which case the exercise decisions were made after the reported exercise date. ${ }^{7}$

Table 1 presents descriptive statistics. The median number of trading days from the grant date to the vesting date is about 250, i.e., a year, for both subsamples. Figure 2 shows the distribution of the vesting periods for the full sample. About a third of the options have a vesting period of one year. Other common vesting periods include, in the order of frequency, 2 years, 0 years (i.e., the options vest immediately), 3 years, 4 years, 6 months, and 5 years. This distribution is largely attributable to the structure of the typical grants. Stand-alone grants (i.e., grants with only one vesting period) represent $40 \%$ of our sample, and about $83 \%$ of these vest in 1 year, 0 years, or 6 months (in that order of frequency). Grants that belong to families with 3, 4, or 5 different vesting periods represent another $53 \%$ of our sample. The norm for family grants with 3 different vesting periods is for the vesting periods to be 1, 2, and 3 years; the norm for family grants with 4 different vesting periods is for the vesting periods to be 1, 2, 3, and 4 years; and the norm for family grants with 5 different vesting periods is for the vesting periods to be 1, 2, 3, 4, and 5 years.

At the time of exercise, both the mean and median remaining life are about four years. Thus, early exercise seems common. However, as Figure 3 illustrates, there is a large variation in the timing of exercises relative to maturity. The exercises are spread fairly evenly in years 3 through 6 , averaging around $1 \%$ per month. But immediately before the options mature, there is a material spike in the fraction of exercises. The fraction of exercises in the last month is $13 \%$ when the acquired shares are not immediately sold and 5\% when the shares are immediately sold.

\footnotetext{
${ }^{7}$ Cicero (2009) also finds evidence of backdating in the subsample of exercises with immediate sales in which the company is the buyer of the shares. Our results are robust to the exclusion of these exercises.
} 
The average fraction of options in a grant that was exercised is $85 \%$ when the acquired shares are not immediately sold and $80 \%$ when the shares are immediately sold. Figure 4 shows the distributions of fraction exercised. The majority of exercises in our sample involve $100 \%$ of the options in a grant, while the other fractions are spread out fairly evenly. In our later analysis, we focus on exercises of $100 \%$ of the options granted.

The descriptive statistics in Table 1 further reveal that the underlying stocks have performed very well leading up to exercises. For example, the average stock return during the prior year is $40 \%$ when the shares were not immediately sold and almost $50 \%$ when the shares were immediately sold. This translates into a high moneyness at the time of the exercise, with averages of about three.

Figure 5 gives further insight into the moneyness at the time of the exercise. The figure presents the average moneyness by the year of exercise. Because stock prices, and therefore the moneyness of option grants tend to drift up over time, we also introduce a control sample that captures this drift. For the control sample, we use the moneyness for the same options at random dates between vesting and the earlier of maturity or delisting. Naturally, the moneyness for the control sample will also be high, because these options are part of the sample and were therefore exercised at some point. But we will nonetheless get a better understanding of the moneyness at the time of the exercise versus the moneyness at other times in the life of the options. The figure shows that the moneyness is high even for exercises in the first year, with an average of almost two. The average moneyness tends to increase gradually for subsequent years, except that there is a clear drop in the last year. In comparison, the control samples exhibit a more modest rise in the moneyness in the first year after the grant, from 1.0 at the time of the grant to an average of about 1.2 after one year. In subsequent years, the average moneyness for the control samples steadily increases, except for between years eight and nine, possibly as a result of many dates for this period coinciding with the economy-wide financial crisis. In sum, the graph suggests that a high moneyness is an important determinant of early exercises, but less so for exercises shortly before maturity. This is consistent with the notion that option holders are reluctant to exercise options early unless most of the option value can be captured upon exercise (Hall and Murphy, 2002). 
Table 1 also gives statistics on the frequency with which the price on the exercise date is the minimum or maximum of all prices during the prior year (i.e, during the twelve months leading to the current date). Heath, Huddart, and Lang (1999) argue that the maximum price is a psychological reference point that affects the exercise decision. The price on the exercise date is at its yearly maximum in about $9 \%$ of the exercises where the shares are not immediately sold and in excess of $16 \%$ when the shares are sold immediately. Both of these statistics are clearly abnormally high, given that one day only represents $0.4 \%$ of all trading days in a year. ${ }^{8}$ The price on the exercise date is at its yearly minimum in $2.2 \%$ of the exercises where the shares are not immediately sold and in $0.3 \%$ when the shares are sold immediately. The fraction of almost 2.2\% seems abnormally high, and likely reflects some backdating to days with low prices for tax purposes when the acquired shares are retained (Cicero, 2009).

Table 1 further reports that CEOs represent 9.9\% (11.9\%) of exercises in which no shares are sold (at least some shares are sold), CFOs represent 5.9\% (10.3\%), and non-executive directors represent 52.7\% (28.8\%). This suggests that CEOs and CFOs are more likely to sell the acquired shares from option exercises than are non-executive directors.

We also estimated the stock and option holdings before the exercises. Other studies obtain similar information from Execucomp. However, Execucomp only provides annual data and is limited to the top five executives for S\&P 1500 firms. Thus, we use a methodology for estimating stock and option holdings using the TFN insider filing database (see Appendix A for a detailed description). We find that the mean

\footnotetext{
${ }^{8}$ For comparison with Cicero (2009), we also estimated the frequency with which the price on the exercise date is at its monthly maximum, where the month is defined as the calendar month of the exercise. Unlike our yearly maximum variable (the maximum over the prior year), the monthly maximum variable encompasses days both before and after the exercise date. As such, a disproportionate number of exercises occurring at the monthly high could reflect either backdating to days when the price was particularly high or simply a tendency to exercise after price run-ups. We find that the price is at its monthly maximum for $7.9 \%$ of the exercise dates in our sample, which is similar to what Cicero reports for his sample.
} 
and median option holdings are larger among insiders who sell the acquired shares, perhaps because this subsample has more executives. In contrast, the mean stock holdings are much larger among insiders who retain their shares. The similarity in median stock holdings suggests that the difference in means is due to extreme shareholdings for a few individuals. ${ }^{9}$

Finally, Table 1 presents statistics on the time value (the Black-Scholes value less the intrinsic value) scaled by the Black-Scholes value. The scaled time value can be viewed as the fraction of money left at the table upon exercise. The mean (median) in cases where the shares are sold immediately is $13.3 \%$ (5.7\%), and when the shares are not immediately sold it is $12.2 \%$ (2.0\%). In comparison, the mean (median) in Bettis, Bizjak, and Lemmon (2005) is somewhat higher at 16\% (10\%).

\subsection{Volatility trends}

Figure 6 shows the volatility for each of the years from the year before the option grants to the last year before the options mature. Total volatility is measured as the standard deviation of stock returns, while

\footnotetext{
${ }^{9}$ For example, our sample includes numerous people who held billions of dollars (directly or indirectly) in the stock of the firms in which they were either insiders or directors. For instance, according to Wal Mart's 2004 proxy, Robson Walton’s direct and indirect holdings (approximately 1.2 billion shares) represented nearly $40 \%$ of the company’s stock. Similarly, Larry Ellison owned 696,356,050 shares of Oracle (approximately 24\%) according to the firm’s 2000 proxy. Other significant holdings include Michael Dell (with over 300 million shares of Dell according to the 2002 proxy), Theodore Waitt (with more than 30\% ownership of Gateway), and Maurice Greenberg of AIG (who owned nearly 47 million shares per AIG's 2005 proxy). In addition to confirming the accuracy of many of the extremely large ownership positions, we excluded observations where the value of direct and indirect holdings that we estimated from the reported holdings records exceeded the market capitalization of the company on the same day. The observations that we excluded for this reason were few ( $0.02 \%$ of the sample) and were obviously the result of filing errors.
} 
systematic (idiosyncratic) volatility is measured as the standard deviation of the predicted (residual) stock returns from the market model. The idiosyncratic volatility exhibits a downward trend, with exception of an increase around year 8 that coincides with the 2008 financial crisis for a bulk of the options. The systematic volatility exhibits a steady or upward trend, with an uptick in year 8 . The total volatility exhibits a downward trend until the onset of the financial crisis around year 8. These trends suggests that exercises during the early part of an option's life will be associated with higher idiosyncratic and total volatility than later exercises, especially if the sample precedes the financial crisis, as in Bettis, Bizjak, and Lemmon (2005).

Table 2 presents regressions of systematic, idiosyncratic, or total volatility during each of the years from the grant to expiration. The independent variables include indicators for the calendar year and a variable indicating the number of years since the grant. The coefficients on the year dummies, especially the 2009 dummy coefficient (which primarily captures the second half of 2008 and the first half of 2009), indicate that both systematic and idiosyncratic volatility increases during the financial crisis. In the regression of idiosyncratic volatility, the coefficient on the number of years since the grant is -0.0006 with a p-value less than $0.001 .^{10}$ This suggests that, on average, the daily idiosyncratic volatility decreases by 0.006 during the 10 -year life of the options. In the regression of systematic volatility, the coefficient on the number of years since the grant is close to zero and statistically insignificant, suggesting that systematic volatility does not change during the life of the options.

The trend for idiosyncratic volatility is consistent with Pástor and Veronesi (2003). Pástor and Veronesi develop a valuation model with learning about average profitability, and they predict that idiosyncratic volatility decreases with firm age. Their empirical results show that the median idiosyncratic return volatility declines monotonically from about 0.11 per month for newly listed firms to about 0.08 for firms that are 20 years old, which implies that the median daily volatility decreases by 0.00033 per year.

\footnotetext{
${ }^{10}$ In alternative specifications, we used indicator variables for each of the years after the grant, and the results suggest that the decline in idiosyncratic volatility is quite monotonic.
} 


\subsection{Methodology}

Past studies on executive stock option exercise behavior commonly estimate regressions for the timing of the options exercise within the life of the options. For example, Hemmer, Matsunaga, and Shevlin (1996), Bettis, Bizjak, and Lemmon (2005) run regressions of the time between the exercise and maturity. These types of analyses are essentially comparisons of early exercises to late exercises. In our first set of regressions, we estimate regressions of the time between exercise and maturity.

However, any analysis that compares early to late exercises in a regression framework introduces challenges in interpretation. This is most evident when we examine the effect of moneyness. Figure 5, which we discussed earlier, shows that the moneyness is higher for late exercises than for early exercises. As we alluded to earlier, this tendency might simply be an artifact of the upward drift in stock prices. When we compare to control groups, the moneyness is relatively higher for early exercises than for late exercises. Thus, a simple comparison of moneyness for early and late exercises (including a regression of exercise timing against moneyness) suggests that executives are less likely to exercise options early when the options are far in-the-money. But a more careful comparison that accounts for the stock price drift suggests the opposite, i.e., that executives are more likely to exercise when the options are far in-the-money.

The previous subsection shows that idiosyncratic volatility also exhibits time-varying trends. The systematic downward trend in idiosyncratic volatility between the grant date and expiration poses a particular challenge in a comparison of early and late exercises. Such a comparison is biased toward showing that early exercises are associated with higher idiosyncratic volatility, and this bias could lead to a flawed interpretation that executives are more likely to exercise options early when the idiosyncratic volatility is high.

To mitigate the problems discussed above, we estimate an alternate set of regressions in the second part of our analysis. In particular, for each year after the grants, we identify options that had vested at the beginning of the year, but had not yet been exercised. Among those options, we compare those that were exercised by the end of the year to those that were not exercised by the end of the year. When estimating 
various time-dependent variables, including moneyness and volatility, we use the actual exercise dates for the sample of options that were exercised during the year and random dates from the same year for the sample of options that were not exercised during the year. If the options are out-of-the-money on the random date, the observation is excluded from the analysis.

\section{Empirical results}

\subsection{Regressions of the time between exercise and maturity}

In our initial analysis, we run regressions of the number of days between the exercise and maturity dates. We do this to facilitate comparison to similar regressions estimated in past studies such as Bettis, Bizjak, and Lemmon (2005) and Klein and Maug (2011). For this analysis (and later analyses), we exclude partial exercises, i.e., exercises of less than $100 \%$ of the grant. The results are similar if we instead include partial exercises. We run the regressions with either total volatility as an independent variable or volatility decomposed into its systematic and idiosyncratic components as independent variables. Further, we run separate regressions for exercises where the acquired shares are immediately sold versus other exercises.

Table 3 presents the regression results. Not surprisingly, given the similarity in research design, the results are largely in line with past studies. Specifically, the results suggest that executives tend to exercise options earlier when the stock price has recently risen, and especially if it has reached a yearly maximum. The exceptions include the market returns between either six months and one month before exercise or twelve months to six months before exercise, which are lower for early exercises in some of the models. Huddart and Lang (1996), Heath, Huddart, and Lang (1999), Bettis, Bizjak, and Lemmon (2005), and Klein and Maug (2011) also report that early exercises are generally more likely to occur after recent stock price run-ups. ${ }^{11}$

\footnotetext{
${ }^{11}$ However, Heath, Huddart, and Lang (1999) report that exercises are negatively related to stock returns the six months ending roughly six months before the exercise. They posit that individuals expect shorterterm stock price trends to reverse and longer-term trends to continue, which is why they exercise after short-
} 
The moneyness of options exercised early is lower than that of those exercised later. Huddart and Lang (1996) report similar results. We are, however, concerned that these findings are largely attributable to a positive stock price drift over time, and are therefore cautious about interpreting them.

CEOs, and, to a lesser extent CFOs and non-executive directors, appear to hold on to their options longer than lower level executives. Moreover, insiders with substantial option holdings appear to be relatively more likely to exercise options early, whereas insiders with substantial stock holdings appear relatively less likely to do the same.

When the shares acquired from the exercise are immediately sold, we find that early exercises are more likely when total volatility is low. But when the shares acquired from the exercise are not immediately sold, we find that early exercises are more likely when total volatility is high. Untabulated results further reveal that, if we constrain the sample to exercises before the 2008 financial crisis, early exercises are more likely when the total volatility is high, irrespective of whether the acquired shares are immediately sold. The latter results are consistent with Hemmer, Matsunaga, and Shevlin (1996), Bettis, Bizjak, and Lemmon (2005), and Klein and Maug (2011). When we decompose volatility, we find that, irrespective of whether the acquired shares are immediately sold, early exercises are more likely when the idiosyncratic volatility is high and the systematic volatility is low.

\subsection{Regressions of the exercise decision}

The regressions in the previous section compare early exercises to late exercises, as has commonly been done in past studies. Again, our concern is that several of the variables exhibit temporal trends. Most

\footnotetext{
term, but not long-term stock price increases. Furthermore, Klein and Maug (2011) report a negative relation between exercises and stock returns over the preceding 52 weeks, but a significant positive relation between the probability of exercise and the stock returns over the prior 156 weeks (roughly 3 years). Finally, Hemmer, Matsunaga, Shevlin (1996) report that early exercises are more likely after stock price declines during the prior 60 trading days.
} 
obviously, stock prices, and, therefore, moneyness, exhibit a positive drift over time. Further, we showed earlier that total and idiosyncratic volatility decline over the life of the options.

In our next set of regressions, we compare decisions to exercise in each of the years between the grant and the maturity to decisions not to exercise in the same years. In particular, for each of these years, we first identify all vested and outstanding options at the beginning of the year. Then we assign random dates from the same years, and define these to be dates on which the options were not exercised. If the options were out-of-the-money on the random dates, we exclude the observations. ${ }^{12}$ Finally, we run multivariate regressions where we compare option exercises to our random control sample of non-exercises. For this analysis, we exclude exercises in the last year, because the uptick of exercises in that year is obviously driven by the impending expiration of the options.

Table 4 presents the results of regressions. Irrespective of whether the acquired shares are immediately sold, there is a strong tendency for exercises to follow stock price run-ups and even coincide with the yearly maximum price. And unlike some of the curious regression results presented in Table 3 and in Heath, Huddart, and Lang (1999) and Hemmer, Matsunaga, Shevlin (1996), there is scant evidence of stock price declines for any period leading up to exercises. The only exception is the market return during the month before exercises when the shares are not immediately sold, which seems abnormally low. But, as noted earlier, this sample is contaminated by manipulation, whereby some of the reported exercise dates are selected ex post facto to be past dates with particularly low prices in order to minimize taxes.

The results further show that exercises are more likely to occur when moneyness is high, and this is particularly pronounced among exercises in the sample of exercises with immediate stock sales. This is in contrast to the earlier regression results, and demonstrates the importance of controlling for stock price

\footnotetext{
${ }^{12}$ Our sample selection criteria yield a sample of options that are in-the-money. The convexity of such options is less pronounced than that for options that are at-the-money. Thus, executives who own the options in our sample should find volatility less appealing than executives who own options at-the-money. In that sense, our sample criteria bias us against finding that executives with options embrace volatility.
} 
drift by comparing early exercises to contemporaneous decisions not to exercise, rather than to later exercises.

Non-executive directors are more likely to delay exercises than other insiders, whereas CEOs and especially CFOs are more inclined to exercise early. Insiders with substantial stock holdings generally exhibit more patience in their exercise behavior, in that they are less likely to exercise early than insiders with low stock holdings.

Now we turn to the volatility results. There is a negative relation between total volatility and both types of exercises. When we decompose volatility, we find that the relation between idiosyncratic volatility and exercises for the sample in which the acquired shares are sold immediately is particularly strong. The idiosyncratic volatility coefficient of -34.895 implies that the probability of exercise decreases from $17.9 \%$ when all variables are set at their respective means to $13.9 \%$ when idiosyncratic volatility increases by one standard deviation. The three other volatility coefficients in the table are also negative, but their p-values, ranging from 0.038 to 0.099 , indicate weaker statistical significance. ${ }^{13}$

As we did for the analysis in Table 3, we repeat the analysis in Table 4 for the sample of exercises before the 2008 financial crisis. We find that the approach in Table 4 is robust to the time period. For example, the total volatility coefficient of -5.873 for the sample for which the shares are not immediately sold changes to -7.540 ( $\mathrm{p}$-value $<0.001$ ) when we use the pre-crisis data, while the total volatility coefficient of -33.077 for the sample for which the shares are immediately sold changes to -34.869 (pvalue $<0.001$ ). Our combined results suggest that the approach in Table 3 yields results that are sensitive to the time period, because it does not consider time-varying volatility. In contrast, the approach in Table 4 considers the time-varying volatility, and, thus, yields robust results across time periods with different aggregate patterns in the time-varying volatility.

As another robustness test, we regressed the exercise decision separately for each year after the grant, using the exercises where the acquired shares are sold immediately. All the independent variables

\footnotetext{
${ }^{13}$ Clustering the standard errors at the firm-level leaves the statistical significance for the main results intact.
} 
are the same as in earlier regressions. Table 5 presents the volatility coefficients for the yearly regressions. The idiosyncratic volatility coefficients are negative in all yearly regressions, and they are statistically significant at the 0.01 level for years 4 through 9 . Thus, we view the negative relation between idiosyncratic volatility and exercise propensity to be robust.

Our results are inconsistent with diversification being a major reason for the exercises. That is, if executives exercise options and sell the acquired shares to diversify personal risk, we would expect this to be more prevalent when the risk is high. When the risk is low, there is little reason to diversify, yet that is when we see more exercises. Furthermore, the diversification motive should be more important for idiosyncratic risk than for systematic risk for two reasons. First, portfolio theory suggests that diversification can more effectively remove idiosyncratic risk than systematic risk. Second, if systematic risk can be hedged, executives who are exposed to risk via undiversifiable equity prefer that the risk be systematic rather than idiosyncratic. Indeed, Armstrong and Vashishtha (2012) argue that "an increase in systematic risk always results in a greater increase in a CEO’s subjective value of his stock-option portfolio than does an equivalent increase in idiosyncratic risk” (p. 86). The implication is that option exercises, e.g., for diversification reasons, are less likely when the systematic risk is high than when the idiosyncratic risk is high. But we find no evidence that the diversification reason is more important for idiosyncratic risk. Quite the contrary, we find that the negative relation between exercises and risk is more evident for idiosyncratic risk.

Our results are consistent with executives placing a higher value on their options when the underlying volatility is high, as predicted by objective option valuation models like the Black-Scholes model. But this begs the question of why executives with options seem to prefer idiosyncratic volatility to systematic volatility, as no such distinction is made in objective option valuation models. We conjecture that executives believe they can better predict, or perhaps even influence, the resolution of idiosyncratic uncertainty than the resolution of systematic uncertainty. This belief could stem from insiders' superior information about firm prospects as well as the many decisions they make on behalf of the firms that affect firm value. As a result, they would rather expose their options to idiosyncratic volatility than systematic 
volatility. To further examine this conjecture, we separately examine the exercise decisions of individuals with varying degrees of insider information and influence in the next section.

\subsection{Results for the subsamples of exercises by CEOs, CFOs, and non-executive directors}

It is likely that the exercise behavior of CEOs/CFOs differs from that of non-executive directors, because CEOs/CFOs have access to more inside information and have greater influence on corporate decisions. Indeed, our conjecture is that the observed preference for idiosyncratic volatility among insiders with stock options is related to such inside information and influence. If so, the preference for idiosyncratic volatility should be more pronounced among CEOs/CFOs than for non-executive directors.

Table 6 reports results for separate logistic regressions of the exercise decisions for CEOs, CFOs, and non-executive directors, all based on the sample of exercises in which the shares are sold immediately. For non-executive directors, the coefficients on systematic and idiosyncratic volatility are both negative and statistically significant and similar in magnitude (-15.1 and -13.0, respectively), suggesting that nonexecutive directors with options place a similar preference on systematic and idiosyncratic volatility. For CEOs and CFOs, the coefficients on idiosyncratic volatility are also negative and statistically significant, but their absolute magnitudes are about three times greater. Furthermore, the coefficients on systematic volatility are statistically insignificant for CEOs and CFOs. Overall, our results suggest that insiders with the best access to inside information and the greatest influence on firm decisions retain their stock options when idiosyncratic uncertainty is high, consistent with our conjecture that such insiders believe they can better predict or influence the resolution of idiosyncratic uncertainty than systematic uncertainty.

\section{Summary and conclusion}

We reexamine the effect of volatility on executives’ decisions to exercise their options. Most prior studies report that high volatility is associated with earlier exercise. But we are concerned that constrained samples and improper benchmark decisions confound interpretations of the reported associations. We

believe that our sample and methodology successfully addresses these issues. In particular, we examine 
the exercises of options for a large sample of grants through their expirations, and compare the decisions to exercise options to contemporaneous decisions not to exercise vested in-the-money options using a long array of explanatory variables.

We find that, ceteris paribus, the likelihood of exercises during the years before the expiration year decreases with volatility, suggesting that executives place a higher value on their options when volatility is high. We further interpret our results to suggest that granting options to executives generally increases their appetite for risk, presumably because the convexity of the option payoffs dominates the concavity of executives’ utility functions.

Our results not only contribute to the literature on option exercises among executives and the literature on valuing ESOs, but also to the vast literature on whether options encourage executives to take on more risk. The effect of options on the incentive to alter risk has proven to be elusive, both in theory and in empirics. Most of the empirical studies examine whether executives with more options (or greater objective convexity stemming from those options) make decisions that inflate risk. Our study provides a different perspective by showing that executives are more likely to retain their options when volatility is high, thus suggesting that the options make executives more welcoming of risk.

We further examine Armstrong and Vashishtha’s (2012) conjecture that executives with options can hedge any unwanted systematic volatility, and thus favor systematic to idiosyncratic volatility. But we also propose an alternative conjecture that executives believe they can better predict and influence the resolution of idiosyncratic uncertainty, and, thus, favor idiosyncratic uncertainty to systematic uncertainty when they have options. Consistent with our alternative conjecture, we report that executives are more likely to retain options when the idiosyncratic volatility is high than when systematic volatility is high. Further corroborating our conjecture, we report that non-executive directors, who presumably have less ability to predict and influence the resolution of idiosyncratic uncertainty, do not exhibit a preference for idiosyncratic volatility to systematic volatility. While our conjecture and that of Armstrong and Vashishtha are not mutually exclusive, our results cast doubt on the notion that executives hedge the systematic risk in their option portfolios. 


\section{Appendix A. Methodology for estimating the value of stock and option holdings}

For each officer or director in our sample, we obtain direct stockholdings, indirect stockholdings, and option holdings from the Thomson Financial Insider Filing database. Stock transactions and stock holdings are reported in Table 1 of the insider filings. Along with any stock transaction, insiders are required to report remaining stockholdings. Remaining direct holdings are reported on the highest sequence number for each Document Control Number (DCN). When an insider reports his/her direct holdings, we retain the reported holdings figure over time (adjusting for stock splits that occur between updates of holdings records) until it is updated with a subsequent holdings record. This yields a time-series of direct holdings for each insider. The determination of indirect shareholdings over time follows substantially the same procedure, except that there might be several types of indirect holdings that are reported separately in Table 1 of the insider filings. Thus, to determine aggregate indirect holdings, we sum up the indirect holdings reported for each DCN and carry this value forward through time (adjusting for stock splits that occur between updates) until it is updated. This creates the time series of indirect holdings for each insider. To value the stock portfolio on a given day, we simply multiply the stock holdings by the prevailing stock price. The value of stock holdings is defined as the sum of the estimated values of direct and indirect stock holdings.

Derivatives transactions and derivatives holdings are reported in Table 2 of the insider filings. The determination of an insider's portfolio of option holdings is a little more complicated than the determination of stock holdings, especially if the insider receives option grants with the same expiration date that have multiple vesting periods and the insider reports each option tranche separately according to both the exercise date and vesting date. Similar to how we aggregate indirect stockholdings, we sum up the total reported option holdings on a given transaction date (or a holdings reporting date) with the same expiration date. We retain the information for the relevant option vintage across time until it is either updated with a subsequent transaction or the options expire. We repeat this process across time for all outstanding maturities of option grants that have not expired, and then aggregate to get the time-series portfolio of options held by each insider. 
To value the options on a given day, we multiply the number of options in each option vintage by the corresponding estimated value per option. Similar to Core and Guay (2002), we employ the BlackScholes (1973) option valuation formula with Merton's (1973) modifications to incorporate dividend yields. This model requires the following inputs: exercise price, time to maturity, current market price, a risk-free rate, and a measure of the volatility for the underlying stock. We obtain exercise prices and expiration dates for each option vintage from the insider filings. We use constant maturity treasury rates from the Federal Reserve (FED) as the risk-free rates. The FED reports these rates for 1, 2, 3, 5, 7, and 10year maturities. We interpolate between the reported years to estimate missing maturities $(4,6,8$, and 9 years). We then round the fractional years to maturity for each option vintage to the nearest full year and select the risk-free rate with the corresponding maturity. For our volatility measure, we first calculate the rolling standard deviation of daily returns over the previous 750 trading days (approximately 3 years). We annualize the daily return standard deviation estimate by multiplying the daily estimate by the square root of the roughly 250 trading days in a year. We estimate dividend yield as the difference between the company's stock returns with and without dividends (both available from CRSP) over the prior 250 trading days. The time to maturity is simply the fractional number of years until the options expire.

The final step before estimating the value of each option vintage is to ensure that our time series of option holdings and exercise prices are properly adjusted for stock splits. Because our methodology essentially retains the most recently reported holding information, the exercise prices and number of options need to be adjusted if a stock split occurs between reporting instances. To accomplish this, we use a combination of the cumulative factor to adjust stock prices (CFACPR) from CRSP upon the first reporting of the option grant and the CFACPR rolling forward on a daily basis. The adjusted exercise price on day $t$ is:

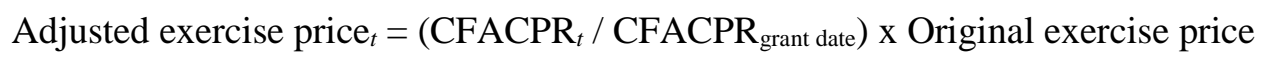

The adjusted number of options on day $t$ is: 
Adjusted number of options $s_{t}=$ Reported number of options $\mathrm{x}$

(Reported exercise price / Adjusted exercise price ) $^{\text {( }}$

The adjustment process ensures that our input into the Black-Scholes model is adjusted for splits. It also resolves issues with late reporting (primarily an issue in the pre-Sarbanes Oxley reporting period), in which an option grant or transaction involving options was reported after a split had occurred and the late filing adjusts for the split.

To prevent our option value estimates from being materially influenced by extreme estimates of dividend yields or stock volatility, we winsorize these two input variables to the 5th and 95th percentiles. We then apply the process described above to estimate the values of all option vintages for each insider on a daily basis. The sum of the values for all option vintages for a given insider is used to find the value of the insider's option portfolio on any given day.

In our analysis, we use the estimated values of stock and option holdings 30 days before the exercise decisions. This ensures that the holdings do not reflect the exercise decisions. 


\section{References}

Agrawal, A., and G. Mandelker, 1987, Managerial incentives and corporate investment and financing decisions, Journal of Finance 42, 823-837.

Armstrong, C. S., and R. Vashishtha, 2012, Executive stock options, differential risk-taking incentives, and firm value, Journal of Financial Economics 104, 70-88.

Berger, P. G., Ofek, E., Yermack, D.L., 1997, Managerial entrenchment and capital structure decisions, Journal of Finance 52, 1411-1438

Bettis, C., J. Bizjak, J. Coles, and S. Kalpathy, 2010, Stock and option grants with performance-based vesting provisions, Review of Financial Studies 23, 3849-3888.

Bettis, J. C., J. Bizjak, J. Coles, and S. Kalpathy, 2015, Performance-vesting provisions in executive compensation, working paper.

Bettis, J. C., J. M. Bizjak, and M. L. Lemmon, 2005, Exercise behavior, valuation, and the incentive effects of employee stock options, Journal of Financial Economics 76, 445-470.

Black, F., and M. Scholes, 1973, The pricing of options and corporate liabilities, Journal of Political Economy 81, 637-654.

Carpenter, J. N., 1998, The exercise and valuation of executive stock options, Journal of Financial Economics 48, 127-158.

Carpenter, J. N., 2000, Does option compensation increase managerial risk appetite? Journal of Finance 55, 2311-2331.

Carpenter, J. N., Richard Stanton, and Nancy Wallace, 2013, The importance of behavioral factors in the exercise and valuation of employee stock options, working paper.

Chava, S., and A. Purnanandam, 2010, CEOs vs. CFOs: Incentives and corporate policies, Journal of Financial Economics 97, 263-278. 
Cicero, D., 2009, The manipulation of executive stock option exercise strategies: information timing and backdating, Journal of Finance 64, 2627-2663.

Cohen, R., B. Hall, and L. Viceira, 2000, Do executive stock options encourage risk-taking? Working paper, Harvard University.

Coles, J. L., N. D. Daniel, and L. Naveen, 2006, Managerial incentives and risk-taking, Journal of Financial Economics 79, 431-468.

Core, J., and W. Guay, 2002, Estimating the value of employee stock option portfolios and their sensitivities to price and volatility, Journal of Accounting Research 40, 613-630.

DeFusco, R., R. Johnson, and T. Zorn, 1990, The effect of executive stock option plans of stockholders and bondholders, Journal of Finance 45, 617-627.

Fos, V., and W. Jiang, 2015, Out-of-the-money CEOs: private control premium and option exercises, Review of Financial Studies, forthcoming.

Gormley, T.A., D.A. Matsa, and T. Milbourn, 2013, CEO compensation and corporate risk-taking: Evidence from a natural experiment, Journal of Accounting and Economics 56, 79-101.

Guay, W., 1999, The sensitive of CEO wealth to equity risk: an analysis of the magnitude and determinants, Journal of Financial Economics 53, 43-71.

Hall, B. J., and K. J. Murphy, 2002, Stock options for undiversified executives, Journal of Accounting and Economics 33, 3-42.

Harris, M., and A. Raviv, 2008, A theory of board control and size, Review of Financial Studies 21, 17971832.

Hayes, R. M., M. Lemmon, and M. Qiu, 2012, Stock options and managerial incentives for risk taking: evidence from FAS 123R, Journal of Financial Economics 105, 174-190. 
Heath, C., S. Huddart, and M. Lang, 1999, Psychological factors and stock option exercise, Quarterly Journal of Economics 114, 601-27.

Hemmer, T., S. Matsunaga, and T. Shevlin, 1996, The influence of risk diversification on the early exercise of employee stock options by executive officers, Journal of Accounting and Economics 21, 45-68.

Huddart, S., and M. Lang, 1996, Employee stock option exercises: An empirical analysis, Journal of Accounting and Economics 21, 5-43.

Izhakian, Y., and D. Yermack, 2014, Risk, ambiguity, and the exercise of employee stock options, working paper.

Jensen, M. C., and W. H. Meckling, 1976, Theory of the firm: managerial behavior, agency costs and ownership structure, Journal of Financial Economics 3, 305-360.

Kalpathy, S., 2009, Stock option repricing and its alternatives: an empirical examination, Journal of Financial and Quantitative Analysis 44, 1459-1487.

Kini, O., and R. Williams, 2012, Tournament incentives, firm risk, and corporate policies, Journal of Financial Economics 103, 350-376.

Klein, D., and E. Maug, 2011, How do executives exercise their stock options?, working paper, University of Mannheim.

Knopf, J. D., J. Nam., and J. H. Thornton, 2002, The volatility and price sensitivities of managerial stock option portfolios and corporate hedging, Journal of Finance 57, 801-813.

Lakonishok, J., and I. Lee, 2001, Are insider trades informative? Review of Financial Studies 13, 79-111.

Lambert, R. A., Larcker, D. F., Verrecchia, R. E., 1991, Portfolio considerations in valuing executive compensation, Journal of Accounting Research 29, 129-149.

Liu, Y., and D. Mauer, 2011, Corporate cash holdings and CEO compensation incentives, Journal of Financial Economics 102, 183-198. 
Low, A., 2009, Managerial risk-taking behavior and equity-based compensation, Journal of Financial Economics 92, 470-490.

Merton, R., 1973, Theory of rational option pricing, Bell Journal of Economics and Management Science 4, 141-183.

Murphy, K. J., 2013, Executive compensation: Where we are, and how we got there," in Constantinides, G., Harris, M., and Stulz, R., eds., Handbook of the Economics of Finance, Elsevier Science North Holland.

Pan, Y., T. Y. Wang, and M. S. Weisbach, 2015, Learning about CEO ability and stock return volatility, Review of Financial Studies 28, 1623-1666.

Pástor, L., and P. Veronesi, 2003, Stock valuation and learning about profitability, Journal of Finance 58, 1749-1789.

Rajgopal, S., and T. Shevlin, 2002, Empirical evidence on the relation between stock option compensation and risk taking, Journal of Accounting and Economics 33, 145-171.

Ross, S. A., 2004, Compensation, incentives, and the duality of risk aversion and riskiness, Journal of Finance 59, 207-225.

Shue, K., and R. S. Townsend, 2013, Swinging for the fences: Executive reactions to quasi-random option grants, working paper.

Smith, C. W., and R. M. Stulz, 1985, The determinants of firms’ hedging policies, Journal of Financial and Quantitative Analysis 20, 391-405.

Tufano, P. 1996, Who manages risk? An empirical examination of risk management practices in the gold mining industries, Journal of Finance 51, 1097-1137. 


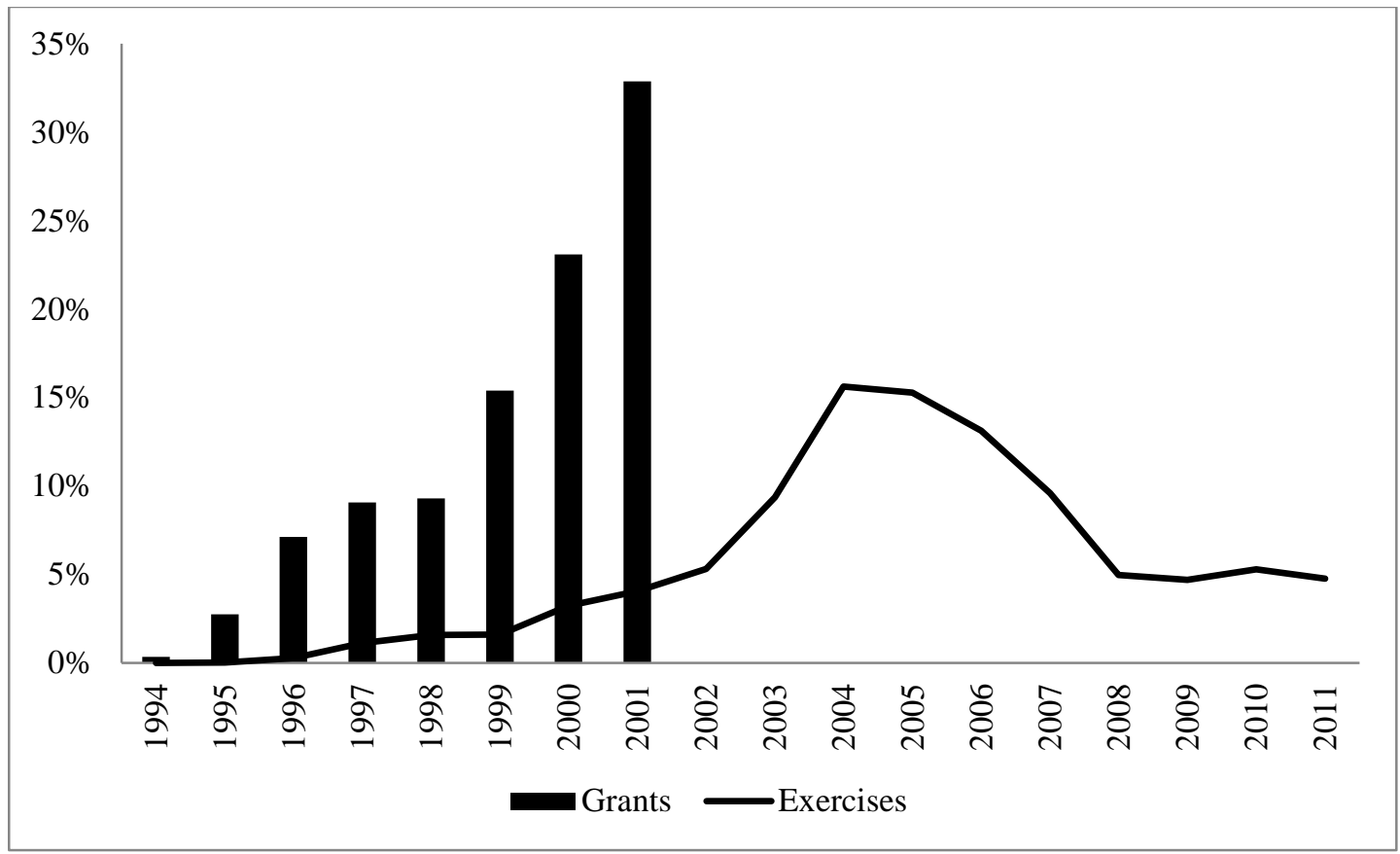

Figure 1

Distribution of sample across time

The graph shows the fractions of the grants and exercises in our sample that occurred in each of the years from 1994 to 2011. 


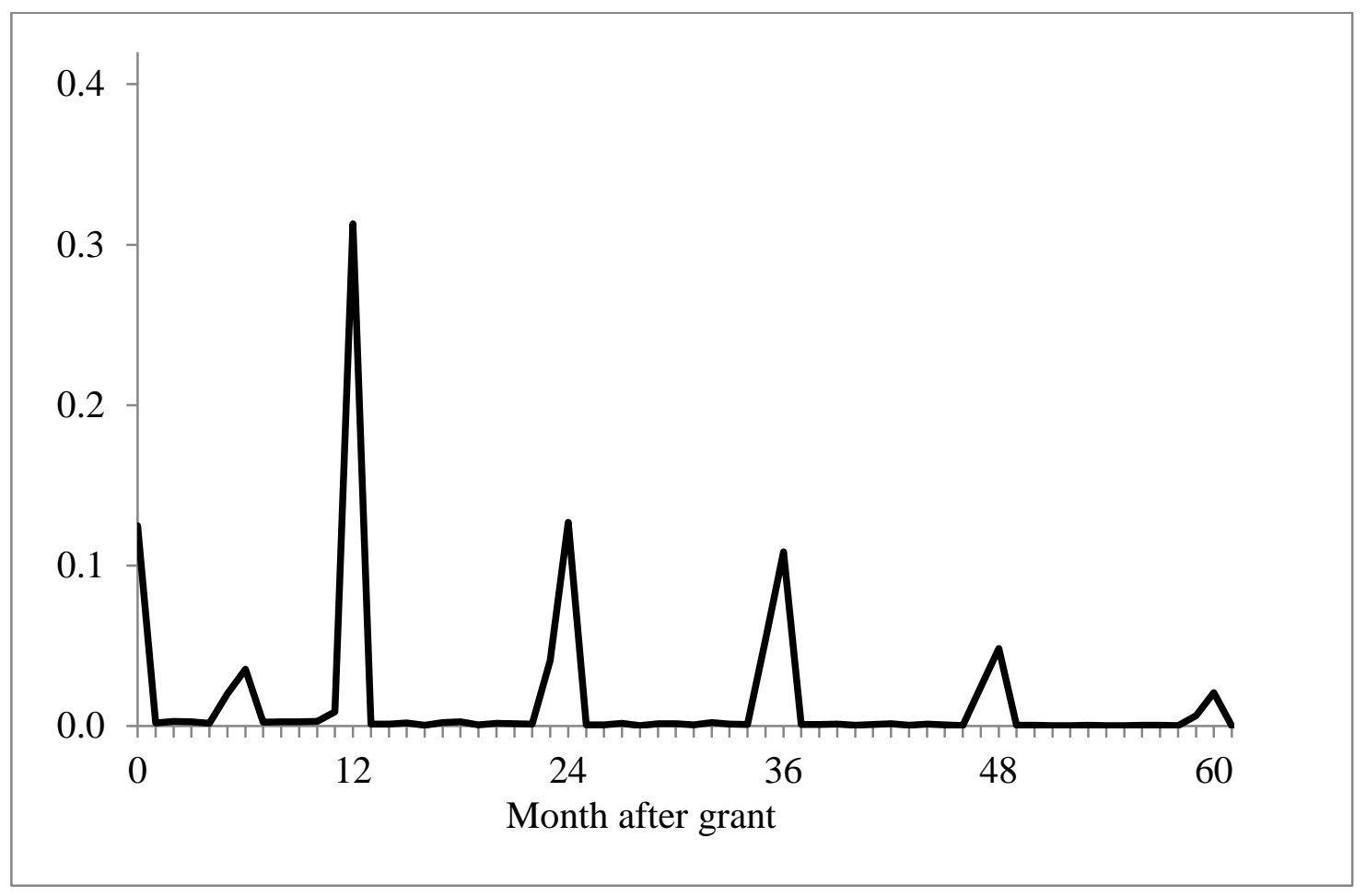

Figure 2

Distribution of vesting periods

The graph shows the distribution of the number months between the grant date and the vesting date for sample of option grants. 


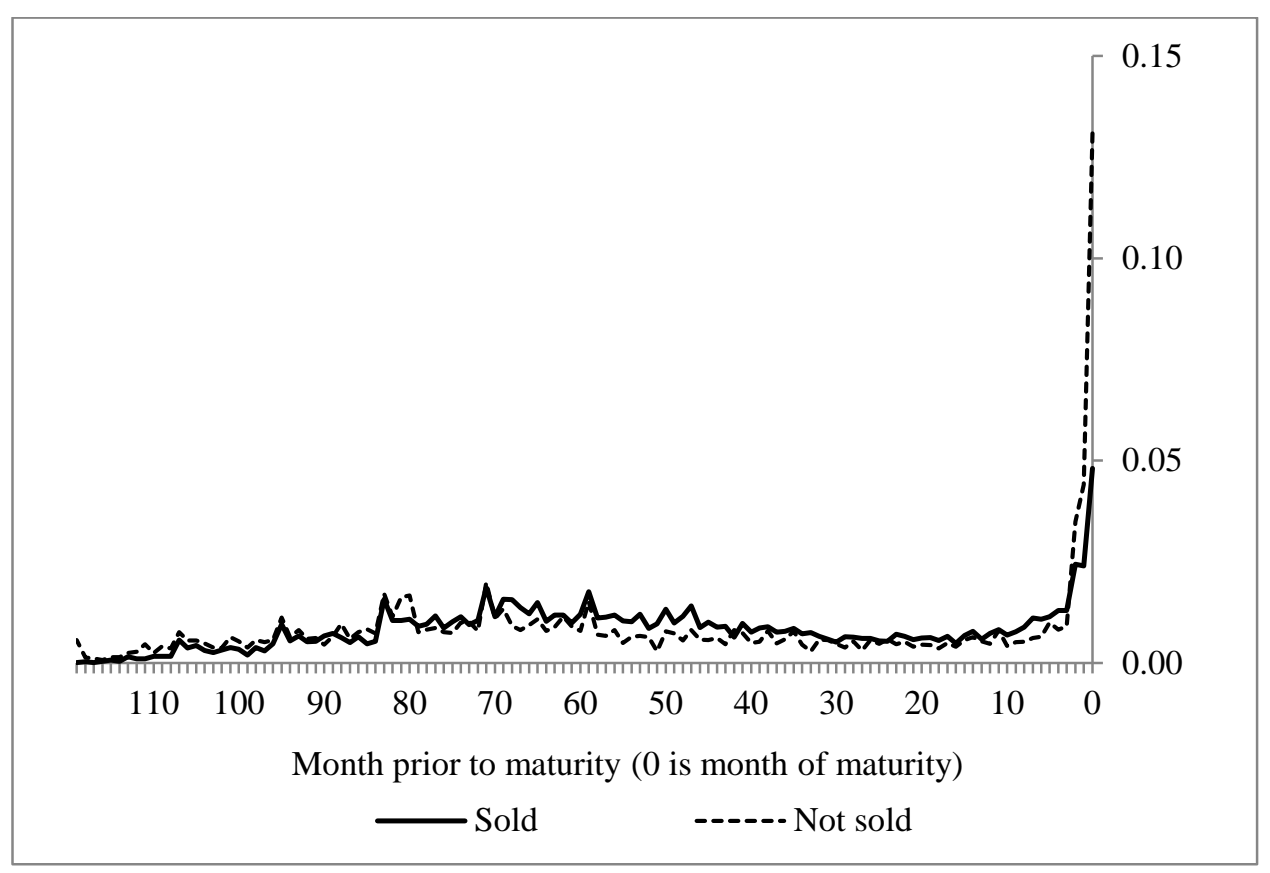

Figure 3

Distribution of exercises from the grant date through maturity

The graph shows the distribution of exercises in our sample in each of the months from the grant date through maturity. Sold indicates that at least some of the shares acquired upon exercise were immediately sold. 


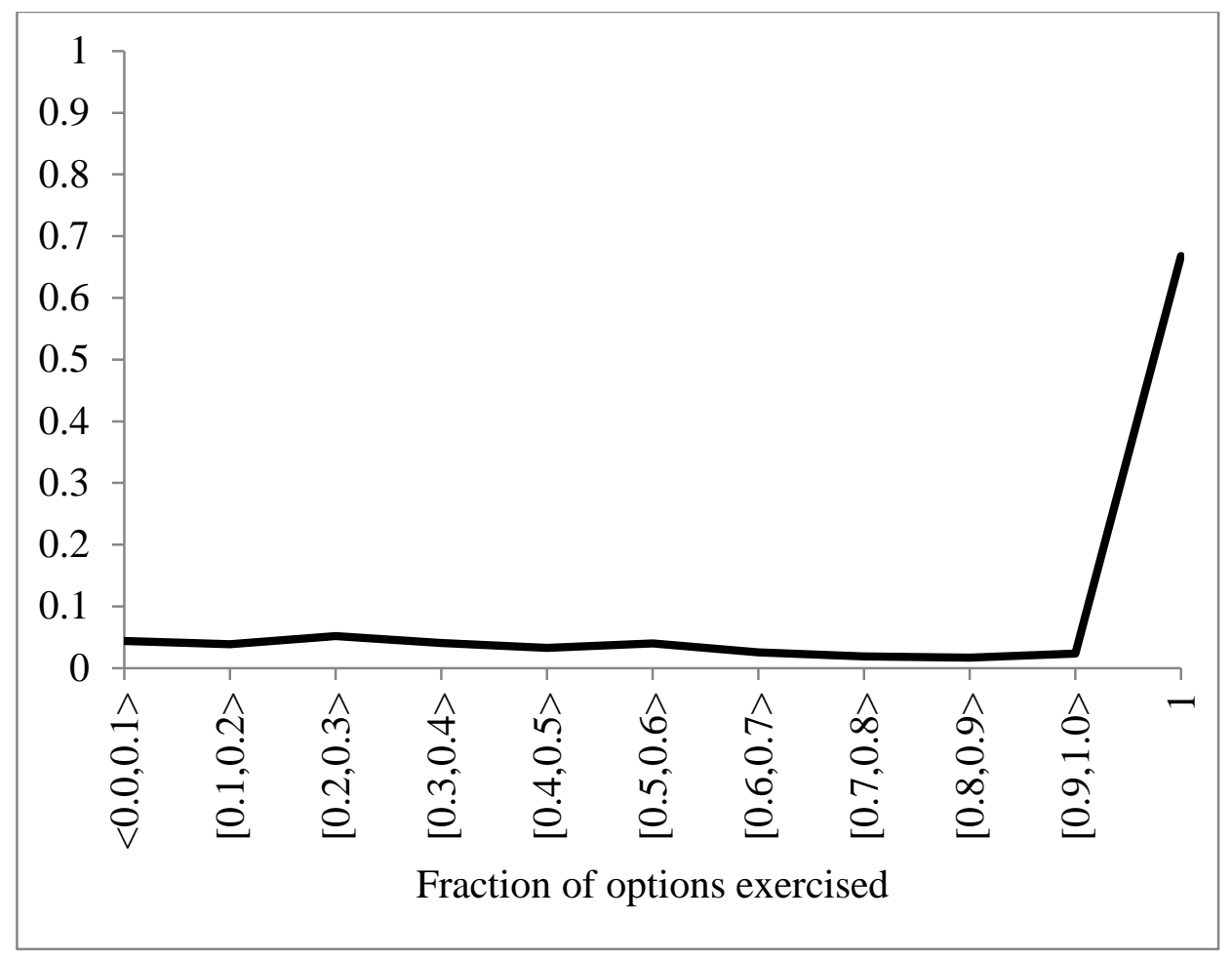

Figure 4

\section{Distribution of fraction of options exercised}

The graph shows the distribution of the fraction of an option grant that was exercised on the same date. An option grant is defined to consist of options that were part of the same grant (i.e., same exercise price, maturity, and vesting date). 


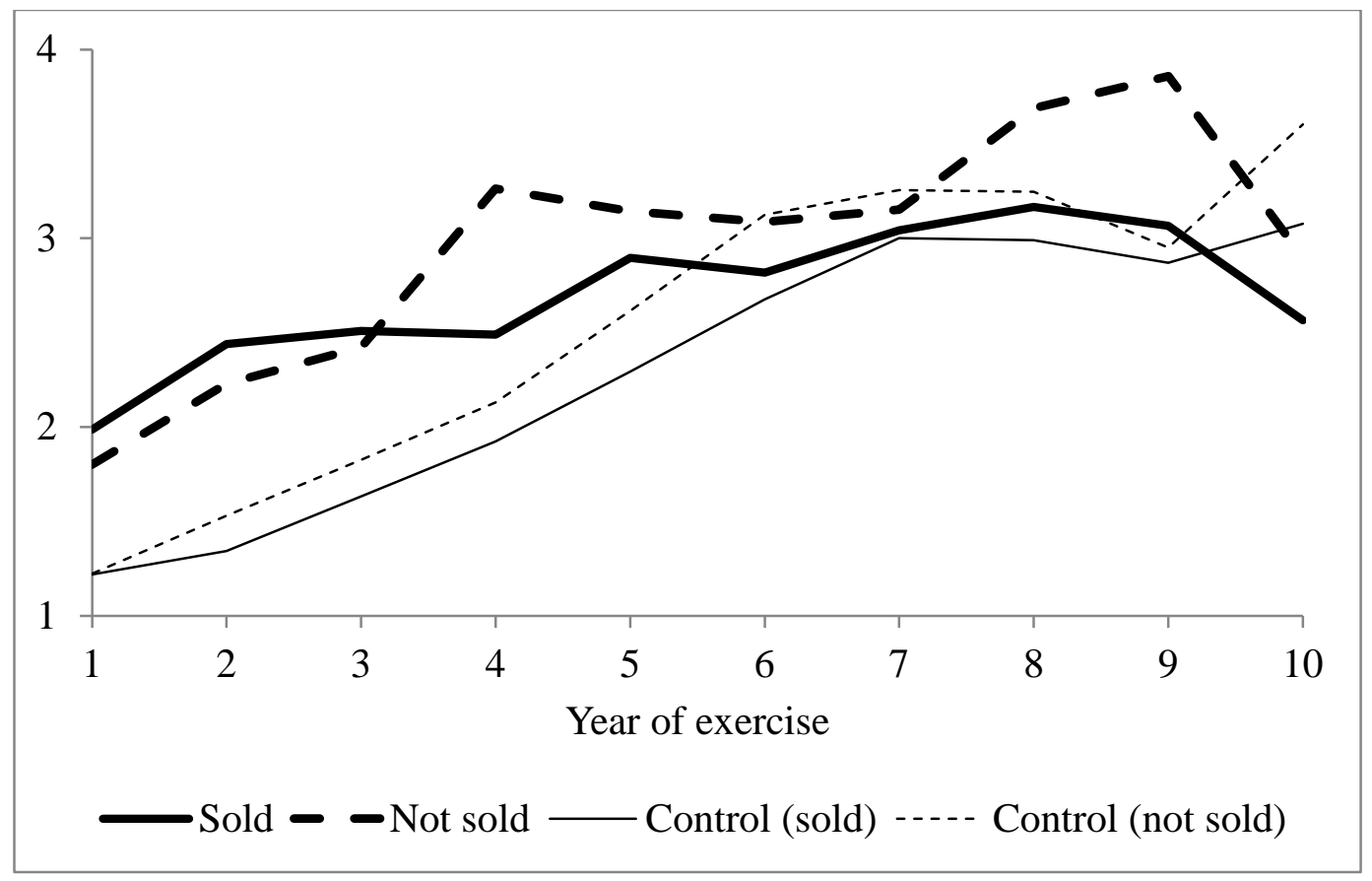

Figure 5

Moneyness by exercise year

The graph shows the average moneyness (the market price scaled by the exercise price) upon exercises, as well as the average moneyness for a control group of randomly drawn dates between vesting the earlier of delisting or maturity (i.e., the moneyness upon exercise had the options been exercised on other dates instead). A year of exercise of 1 means that the options were exercised in the first year after the grant, etc. Sold indicates that at least some of the shares acquired upon exercise were immediately sold. 


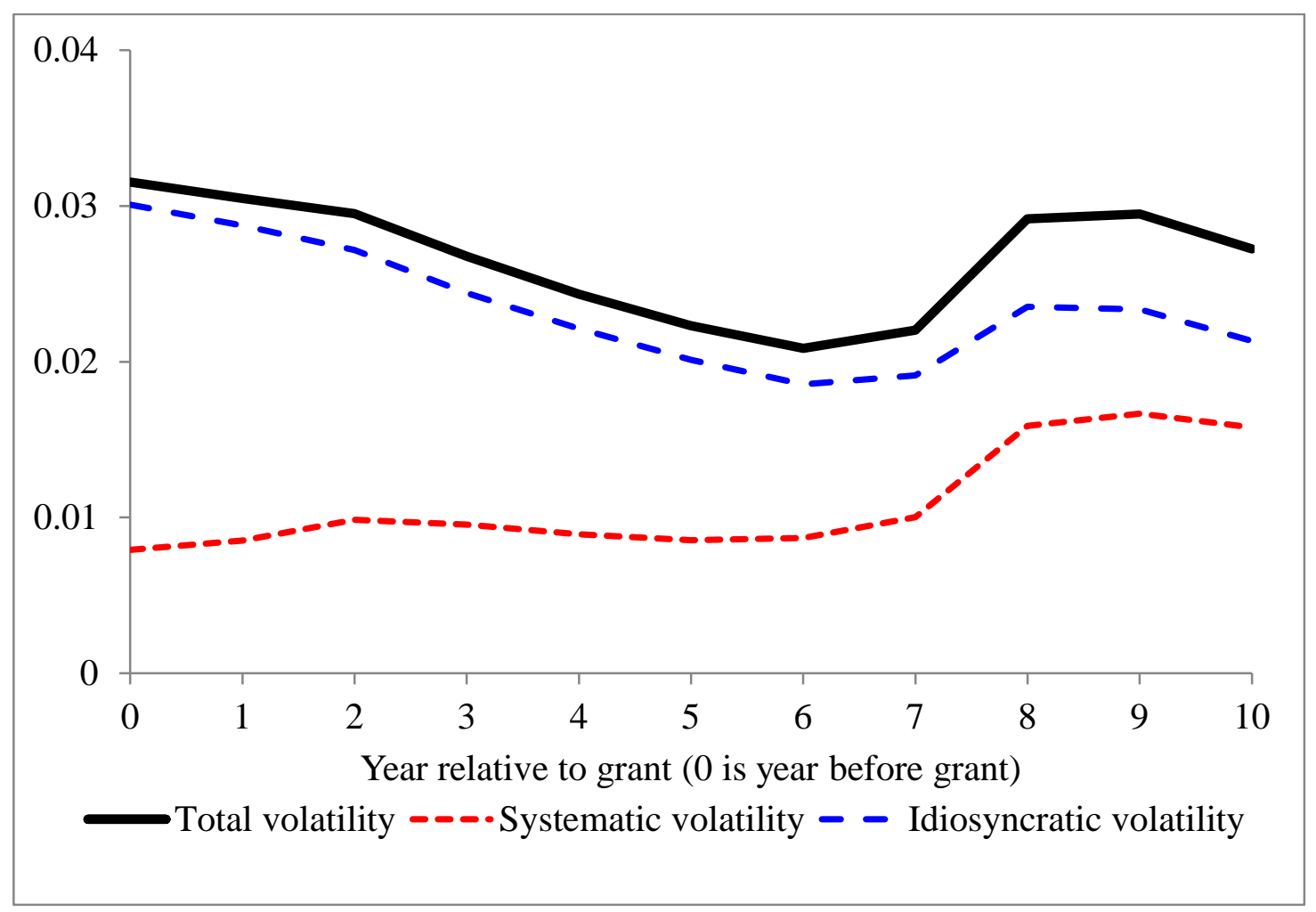

Figure 6

Volatility during the years from the grant to maturity of options

The graph shows the average daily volatility during each of the years from the year leading up to the option grants to the last year before the options mature. Total volatility is measured as the standard deviation of stock returns. Systematic (idiosyncratic) volatility is measured as the standard deviation of the predicted (residual) stock returns from the market model. The standard deviations are not additive, such that the sum of the systematic and idiosyncratic volatilities exceeds the total volatility. 


\section{Table 1 \\ Descriptive statistics}

The table presents descriptive statistics for our sample of exercises between 1994 and 2011. The sample only includes exercises of in-the-money or at-the-money options that are not associated with mergers. (Dispositions to the issuer of issuer equity securities pursuant to Rule 16b-3(e) and cancellations are excluded.) The sample has been bifurcated into exercises where at least some of the acquired shares were immediately sold $(n=8,689)$ and others ( $\mathrm{n}=28,641)$. Appendix A describes the methodology for estimating the values of option and stock holdings. Time value is estimated as one minus the ratio of the intrinsic value upon exercise to the Black-Scholes value.

\begin{tabular}{|c|c|c|c|c|}
\hline & \multicolumn{2}{|c|}{$\begin{array}{c}\text { Shares are not } \\
\text { immediately sold }\end{array}$} & \multicolumn{2}{|c|}{$\begin{array}{c}\text { Shares are } \\
\text { immediately sold }\end{array}$} \\
\hline & Mean & Median & Mean & Median \\
\hline Trading days from grant to vesting & 365 & 253 & 440 & 255 \\
\hline Trading days from vesting to exercise & 1174 & 1081 & 1064 & 979 \\
\hline Trading days from exercise to maturity & 976 & 1032 & 1012 & 1074 \\
\hline Fraction of options exercised & 0.853 & 1.000 & 0.799 & 1.000 \\
\hline Standard deviation of stock returns (daily) & 0.025 & 0.021 & 0.023 & 0.020 \\
\hline Stock price is at its yearly minimum & 0.022 & 0.000 & 0.003 & 0.000 \\
\hline Stock price is at its yearly maximum & 0.089 & 0.000 & 0.166 & 0.000 \\
\hline Stock return one month before exercise & 0.024 & 0.015 & 0.070 & 0.053 \\
\hline Market return one month before exercise & 0.005 & 0.013 & 0.013 & 0.017 \\
\hline Stock return six months before exercise & 0.196 & 0.138 & 0.280 & 0.196 \\
\hline Market return six months before exercise & 0.052 & 0.072 & 0.072 & 0.079 \\
\hline Stock return year before exercise & 0.399 & 0.232 & 0.494 & 0.316 \\
\hline Market return year before exercise & 0.106 & 0.130 & 0.129 & 0.140 \\
\hline Moneyness upon exercise & 3.111 & 2.148 & 2.914 & 2.053 \\
\hline Dividend yield & 0.015 & 0.008 & 0.012 & 0.006 \\
\hline CEO & 0.099 & 0.000 & 0.119 & 0.000 \\
\hline CFO & 0.059 & 0.000 & 0.103 & 0.000 \\
\hline Director (non-executive) & 0.527 & 1.000 & 0.288 & 0.000 \\
\hline Value of option holdings (thousands of dollars) & 5,588 & 471 & 8,356 & 1,438 \\
\hline Value of share holdings (thousands of dollars) & 100,497 & 718 & 10,925 & 777 \\
\hline Time value & 0.122 & 0.020 & 0.133 & 0.057 \\
\hline
\end{tabular}




\section{Table 2 \\ Volatility regressions}

This table presents results from regressions of systematic, idiosyncratic, or total volatility during each of the years from the year leading up to the option grants to the last year before the options mature. Total volatility is measured as the daily standard deviation of stock returns. Systematic (idiosyncratic) volatility is measured as the standard deviation of the predicted (residual) stock returns from the market model. Years after grant indicate the number of years after the grant date ( 0 is the year leading up to the grant, 1 is the year following the grant, and so on). The year dummies indicate the calendar year of the end of the measurement period (e.g., if the standard deviation is measured from July 1, 2005, to June 30, 2006, then the dummy for 2006 equals one). The sample size is 274,274 observations. p-values are based on heteroskedasticity-consistent standard errors.

\begin{tabular}{|c|c|c|c|c|c|c|}
\hline & \multicolumn{2}{|c|}{ Systematic volatility } & \multicolumn{2}{|c|}{ Idiosyncratic volatility } & \multicolumn{2}{|c|}{ Total volatility } \\
\hline & Coeff. & p-value & Coeff. & p-value & Coeff. & p-value \\
\hline Intercept & 0.004 & 0.000 & 0.024 & 0.000 & 0.024 & 0.000 \\
\hline Years after grant & 0.0000 & 0.809 & -0.0006 & 0.000 & -0.0006 & 0.000 \\
\hline 1997 & 0.001 & 0.000 & -0.001 & 0.053 & 0.000 & 0.350 \\
\hline 1998 & 0.004 & 0.000 & 0.000 & 0.201 & 0.001 & 0.000 \\
\hline 1999 & 0.004 & 0.000 & 0.006 & 0.000 & 0.007 & 0.000 \\
\hline 2000 & 0.002 & 0.000 & 0.008 & 0.000 & 0.008 & 0.000 \\
\hline 2001 & 0.005 & 0.000 & 0.009 & 0.000 & 0.011 & 0.000 \\
\hline 2002 & 0.006 & 0.000 & 0.004 & 0.000 & 0.006 & 0.000 \\
\hline 2003 & 0.007 & 0.000 & 0.003 & 0.000 & 0.005 & 0.000 \\
\hline 2004 & 0.004 & 0.000 & -0.002 & 0.000 & -0.001 & 0.001 \\
\hline 2005 & 0.003 & 0.000 & -0.003 & 0.000 & -0.002 & 0.000 \\
\hline 2006 & 0.003 & 0.000 & -0.003 & 0.000 & -0.002 & 0.000 \\
\hline 2007 & 0.004 & 0.000 & -0.003 & 0.000 & -0.002 & 0.000 \\
\hline 2008 & 0.009 & 0.000 & 0.003 & 0.000 & 0.007 & 0.000 \\
\hline 2009 & 0.025 & 0.000 & 0.016 & 0.000 & 0.026 & 0.000 \\
\hline 2010 & 0.013 & 0.000 & 0.005 & 0.000 & 0.010 & 0.000 \\
\hline 2011 & 0.009 & 0.000 & -0.001 & 0.023 & 0.004 & 0.000 \\
\hline R-squared & 0.418 & & 0.182 & & 0.234 & \\
\hline
\end{tabular}




\section{Table 3}

\section{Regressions of time between exercise and maturity}

This table presents results from regressions of the number of days between exercise and maturity against a set of explanatory variables. The sample includes $100 \%$ exercises (i.e., partial exercises are excluded). A positive coefficient suggests that a higher value for the variable is associated with earlier exercise. Abnormal stock returns are estimated as the difference between the stock returns and the value-weighted market returns. Total volatility is measured as the daily standard deviation of stock returns. Systematic (idiosyncratic) volatility is measured as the standard deviation of the predicted (residual) stock returns from the market model. Indicator variables for the 48 Fama and French industries are included in all models. p-values are based on heteroskedasticity-consistent standard errors.

\begin{tabular}{|c|c|c|c|c|c|c|c|c|}
\hline & \multicolumn{4}{|c|}{$\begin{array}{l}\text { Shares are not immediately sold } \\
\qquad(\mathrm{n}=6,377)\end{array}$} & \multicolumn{4}{|c|}{$\begin{array}{l}\text { Shares are immediately sold } \\
\qquad(\mathrm{n}=17,870)\end{array}$} \\
\hline & Coeff. & p-value & Coeff. & p-value & Coeff. & p-value & Coeff. & p-value \\
\hline Intercept & 1,571 & 0.000 & 934 & 0.000 & 1,544 & 0.000 & 1,071 & 0.000 \\
\hline Trading days from grant to vesting & -0.2 & 0.000 & -0.1 & 0.005 & -0.2 & 0.000 & -0.1 & 0.000 \\
\hline Total stock return volatility & 2,285 & 0.014 & & & $-4,562$ & 0.000 & & \\
\hline Systematic stock return volatility & & & $-37,002$ & 0.000 & & & $-36,760$ & 0.000 \\
\hline Idiosyncratic stock return volatility & & & 18,926 & 0.000 & & & 16,825 & 0.000 \\
\hline Stock price is at its yearly minimum & -111 & 0.036 & -96 & 0.059 & -340 & 0.000 & -401 & 0.000 \\
\hline Stock price is at its yearly maximum & 112 & 0.000 & 101 & 0.000 & 19 & 0.112 & 44 & 0.000 \\
\hline Abnormal stock return one month before exercise & 288 & 0.000 & 124 & 0.125 & 292 & 0.000 & 111 & 0.011 \\
\hline Market return one month before exercise & 106 & 0.579 & 593 & 0.001 & 48 & 0.702 & 631 & 0.000 \\
\hline Abn. stock return six months to one month before exercise & 156 & 0.000 & 44 & 0.024 & 285 & 0.000 & 83 & 0.000 \\
\hline Market return six months to one month before exercise & -228 & 0.009 & -74 & 0.325 & -218 & 0.000 & 31 & 0.486 \\
\hline Abn. stock return twelve to six months before exercise & 91 & 0.000 & 31 & 0.065 & 87 & 0.000 & 53 & 0.000 \\
\hline Market return twelve to six months before exercise & -12 & 0.867 & -206 & 0.001 & -41 & 0.215 & -175 & 0.000 \\
\hline Moneyness upon exercise & -48 & 0.000 & -56 & 0.000 & -18 & 0.000 & -27 & 0.000 \\
\hline Moneyness upon exercise squared & 1.0 & 0.000 & 1.3 & 0.000 & 0.1 & 0.301 & 0.3 & 0.000 \\
\hline Dividend yield & $-1,983$ & 0.001 & -447 & 0.415 & $-4,185$ & 0.000 & $-1,922$ & 0.000 \\
\hline CEO & -210 & 0.000 & -248 & 0.000 & -269 & 0.000 & -291 & 0.000 \\
\hline CFO & -173 & 0.000 & -161 & 0.000 & -93 & 0.000 & -93 & 0.000 \\
\hline Director (non-executive) & -212 & 0.000 & -107 & 0.000 & -238 & 0.000 & -169 & 0.000 \\
\hline Logarithm of the value of option holdings & 22 & 0.000 & 48 & 0.000 & 41 & 0.000 & 60 & 0.000 \\
\hline Logarithm of the value of share holdings & -39 & 0.000 & -28 & 0.000 & -45 & 0.000 & -34 & 0.000 \\
\hline R-squared & 0.228 & & 0.342 & & 0.231 & & 0.336 & \\
\hline
\end{tabular}




\section{Table 4}

\section{Logistic regressions of the choice to exercise options}

This table presents regressions of the decision to exercise options that have vested and are in-the-money. The sample includes $100 \%$ exercises (i.e., partial exercises are excluded) and a control group of vested options that are not exercised in a given year. The latter group of options have been assigned a hypothetical exercise date that is randomly drawn from the given year, and options are excluded if they are out-of-the-money on the hypothetical exercise date. Abnormal stock returns are estimated as the difference between the stock returns and the value-weighted market returns. Total volatility is measured as the daily standard deviation of stock returns. Systematic (idiosyncratic) volatility is measured as the standard deviation of the predicted (residual) stock returns from the market model. $N$ ex indicates the number of exercises in the sample and $N$ non-ex indicates the number of control observations. Indicator variables for the 48 Fama and French industries are included in all models.

\begin{tabular}{|c|c|c|c|c|c|c|c|c|}
\hline & \multicolumn{4}{|c|}{$\begin{array}{c}\text { Shares are not immediately sold } \\
(\mathrm{N} \text { ex }=3,841 ; \mathrm{N} \text { non-ex }=20,262)\end{array}$} & \multicolumn{4}{|c|}{$\begin{array}{c}\text { Shares are immediately sold } \\
(\mathrm{N} \text { ex }=12,884 ; \mathrm{N} \text { non-ex }=46,315)\end{array}$} \\
\hline & Coeff. & p-value & Coeff. & p-value & Coeff. & p-value & Coeff. & p-value \\
\hline Intercept & -0.780 & 0.209 & -0.790 & 0.202 & 2.962 & 0.000 & 2.673 & 0.000 \\
\hline Trading days from grant to vesting & 0.044 & 0.000 & 0.045 & 0.000 & 0.052 & 0.000 & 0.051 & 0.000 \\
\hline Trading days from vesting to exercise & -0.012 & 0.705 & -0.012 & 0.704 & 0.085 & 0.000 & 0.092 & 0.000 \\
\hline Trading days from exercise to maturity & -0.144 & 0.006 & -0.155 & 0.004 & -0.561 & 0.000 & -0.515 & 0.000 \\
\hline Total stock return volatility & -5.873 & 0.001 & & & -33.077 & 0.000 & & \\
\hline Systematic stock return volatility & & & -6.220 & 0.072 & & & -3.888 & 0.099 \\
\hline Idiosyncratic stock return volatility & & & -3.991 & 0.038 & & & -34.895 & 0.000 \\
\hline Stock price is at its yearly minimum & 0.758 & 0.000 & 0.755 & 0.000 & -0.671 & 0.002 & -0.665 & 0.002 \\
\hline Stock price is at its yearly maximum & 0.519 & 0.000 & 0.521 & 0.000 & 0.612 & 0.000 & 0.610 & 0.000 \\
\hline Abnormal stock return 1 month before exercise & 0.310 & 0.041 & 0.302 & 0.047 & 4.714 & 0.000 & 4.730 & 0.000 \\
\hline Market return 1 month before exercise & -0.886 & 0.028 & -0.860 & 0.033 & 5.099 & 0.000 & 4.935 & 0.000 \\
\hline Abn. stock return 6 to 1 month before exercise & 0.400 & 0.000 & 0.383 & 0.000 & 1.273 & 0.000 & 1.297 & 0.000 \\
\hline Market return 6 to 1 month before exercise & 1.024 & 0.000 & 1.023 & 0.000 & 2.539 & 0.000 & 2.460 & 0.000 \\
\hline Abn. stock return 12 to 6 months before exercise & 0.118 & 0.000 & 0.112 & 0.000 & 0.364 & 0.000 & 0.375 & 0.000 \\
\hline Market return 12 to 6 months before exercise & 0.689 & 0.000 & 0.674 & 0.000 & 1.005 & 0.000 & 1.085 & 0.000 \\
\hline Moneyness upon exercise & 0.158 & 0.000 & 0.158 & 0.000 & 0.223 & 0.000 & 0.228 & 0.000 \\
\hline Moneyness upon exercise squared & -0.005 & 0.000 & -0.005 & 0.000 & -0.007 & 0.000 & -0.007 & 0.000 \\
\hline Dividend yield & 3.352 & 0.017 & 3.441 & 0.014 & 0.042 & 0.968 & -0.130 & 0.901 \\
\hline CEO & 0.104 & 0.188 & 0.096 & 0.225 & 0.092 & 0.034 & 0.102 & 0.020 \\
\hline CFO & 0.232 & 0.011 & 0.227 & 0.013 & 0.234 & 0.000 & 0.234 & 0.000 \\
\hline Director (non-executive) & -0.161 & 0.000 & -0.153 & 0.001 & -0.388 & 0.000 & -0.399 & 0.000 \\
\hline Logarithm of the value of option holdings & 0.005 & 0.673 & 0.010 & 0.441 & 0.027 & 0.001 & 0.021 & 0.010 \\
\hline Logarithm of the value of share holdings & -0.045 & 0.000 & -0.044 & 0.000 & -0.051 & 0.000 & -0.052 & 0.000 \\
\hline
\end{tabular}




\section{Table 5}

\section{Logistic regressions of the choice to exercise options by year}

This table presents regressions of the decision to exercise options that have vested and are in-the-money. Separate regressions are run for each year after the grant date. The sample includes $100 \%$ exercises (i.e., partial exercises are excluded) where the shares are immediately sold and a control group of vested options that are not exercised in a given year. The latter group of options have been assigned a hypothetical exercise date that is randomly drawn from the given year, and options are excluded if they are out-of-the-money on the hypothetical exercise date. Abnormal stock returns are estimated as the difference between the stock returns and the value-weighted market returns. Total volatility is measured as the daily standard deviation of stock returns. Systematic (idiosyncratic) volatility is measured as the standard deviation of the predicted (residual) stock returns from the market model. Panel A presents results with systematic and idiosyncratic volatility as independent variables. Panel B present results with total volatility as an independent variable (in place of systematic and idiosyncratic volatility). Only the volatility coefficients are presented for brevity. Coefficients are given with p-values in parentheses.

\begin{tabular}{|c|c|c|c|c|c|c|c|c|c|}
\hline & Year 1 & Year 2 & Year 3 & Year 4 & Year 5 & Year 6 & Year 7 & Year 8 & Year 9 \\
\hline \multicolumn{10}{|l|}{ Panel A: Volatility is decomposed } \\
\hline Systematic stock return volatility & $\begin{array}{r}2.442 \\
(0.932)\end{array}$ & $\begin{array}{r}0.005 \\
(0.999)\end{array}$ & $\begin{array}{r}5.951 \\
(0.446)\end{array}$ & $\begin{array}{r}-3.565 \\
(0.648)\end{array}$ & $\begin{array}{r}-10.494 \\
(0.145)\end{array}$ & $\begin{array}{r}-12.884 \\
(0.098)\end{array}$ & $\begin{array}{c}19.049 \\
(0.029)\end{array}$ & $\begin{array}{r}11.984 \\
(0.128)\end{array}$ & $\begin{array}{r}3.402 \\
(0.553)\end{array}$ \\
\hline Idiosyncratic stock return volatility & $\begin{array}{r}-21.010 \\
(0.128)\end{array}$ & $\begin{array}{r}-13.014 \\
(0.018)\end{array}$ & $\begin{array}{r}-8.318 \\
(0.062)\end{array}$ & $\begin{array}{r}-45.350 \\
(0.000)\end{array}$ & $\begin{array}{r}-43.715 \\
(0.000)\end{array}$ & $\begin{array}{r}-34.353 \\
(0.000)\end{array}$ & $\begin{array}{r}-39.454 \\
(0.000)\end{array}$ & $\begin{array}{r}-44.395 \\
(0.000)\end{array}$ & $\begin{array}{r}-32.758 \\
(0.000)\end{array}$ \\
\hline \multicolumn{10}{|l|}{ Panel B: Volatility is not decomposed } \\
\hline Total stock return volatility & $\begin{array}{r}-19.827 \\
(0.111)\end{array}$ & $\begin{array}{r}-13.222 \\
(0.013) \\
\end{array}$ & $\begin{array}{r}-7.925 \\
(0.065) \\
\end{array}$ & $\begin{array}{r}-46.020 \\
(0.000)\end{array}$ & $\begin{array}{r}-45.418 \\
(0.000)\end{array}$ & $\begin{array}{r}-37.480 \\
(0.000)\end{array}$ & $\begin{array}{r}-30.087 \\
(0.000)\end{array}$ & $\begin{array}{r}-30.856 \\
(0.000)\end{array}$ & $\begin{array}{r}-21.015 \\
(0.000)\end{array}$ \\
\hline
\end{tabular}




\section{Table 6 \\ Logistic regressions of the choice to exercise options by affiliation}

This table presents regressions of the decision to exercise options that have vested and are in-the-money by affiliation with the company (either CEO, CFO, or non-executive director). The sample includes $100 \%$ exercises (i.e., partial exercises are excluded) where the shares are immediately sold and a control group of vested options that are not exercised in a given year. The latter group of options have been assigned a hypothetical exercise date that is randomly drawn from the given year, and options are excluded if they are out-of-the-money on the hypothetical exercise date. Abnormal stock returns are estimated as the difference between the stock returns and the value-weighted market returns. Total volatility is measured as the daily standard deviation of stock returns. Systematic (idiosyncratic) volatility is measured as the standard deviation of the predicted (residual) stock returns from the market model. Panel A presents results with systematic and idiosyncratic volatility as independent variables. Panel B present results with total volatility as an independent variable (in place of systematic and idiosyncratic volatility), but only the coefficient for total volatility is presented for brevity. $N$ ex indicates the number of exercises in the sample and $N$ non-ex indicates the number of control observations. Indicator variables for the 48 Fama and French industries are included in all models.

\begin{tabular}{|c|c|c|c|c|c|c|}
\hline & \multicolumn{2}{|c|}{$\begin{array}{c}\text { CEOs } \\
\mathrm{N} \text { ex }=1,070 \\
\mathrm{~N} \text { non-ex }=3,301\end{array}$} & \multicolumn{2}{|c|}{$\begin{array}{c}\text { CFOs } \\
\mathrm{N} \text { ex }=1,275 \\
\mathrm{~N} \text { non-ex }=3,334\end{array}$} & \multicolumn{2}{|c|}{$\begin{array}{c}\text { Directors } \\
\mathrm{N} \text { ex }=4,390 \\
\mathrm{~N} \text { non-ex }=20,009\end{array}$} \\
\hline & Coeff. & p-value & Coeff. & p-value & Coeff. & p-value \\
\hline \multicolumn{7}{|l|}{ Panel A: Volatility is decomposed } \\
\hline Intercept & 6.566 & 0.000 & 3.651 & 0.058 & -1.245 & 0.135 \\
\hline Trading days from grant to vesting & 0.052 & 0.053 & 0.096 & 0.000 & 0.034 & 0.000 \\
\hline Trading days from vesting to exercise & 0.102 & 0.201 & 0.153 & 0.036 & 0.146 & 0.000 \\
\hline Trading days from exercise to maturity & -1.006 & 0.000 & -0.756 & 0.000 & -0.498 & 0.000 \\
\hline Systematic stock return volatility & 3.904 & 0.621 & -15.834 & 0.068 & -15.141 & 0.000 \\
\hline Idiosyncratic stock return volatility & -47.125 & 0.000 & -41.204 & 0.000 & -12.996 & 0.000 \\
\hline Stock price is at its yearly minimum & -13.266 & 0.971 & -0.466 & 0.448 & -0.431 & 0.174 \\
\hline Stock price is at its yearly maximum & 0.306 & 0.028 & 0.866 & 0.000 & 0.482 & 0.000 \\
\hline Abnormal stock return 1 month before exercise & 5.616 & 0.000 & 5.579 & 0.000 & 3.490 & 0.000 \\
\hline Market return 1 month before exercise & 7.579 & 0.000 & 6.115 & 0.000 & 3.867 & 0.000 \\
\hline Abn. stock return 6 to 1 month before exercise & 0.963 & 0.000 & 0.854 & 0.000 & 1.187 & 0.000 \\
\hline Market return 6 to 1 month before exercise & 2.562 & 0.000 & 1.783 & 0.000 & 2.500 & 0.000 \\
\hline Abn. stock return 12 to 6 months before exercise & 0.381 & 0.005 & 0.192 & 0.050 & 0.327 & 0.000 \\
\hline Market return 12 to 6 months before exercise & 1.030 & 0.002 & 1.240 & 0.000 & 0.971 & 0.000 \\
\hline Moneyness upon exercise & 0.541 & 0.000 & 0.277 & 0.000 & 0.189 & 0.000 \\
\hline Moneyness upon exercise squared & -0.029 & 0.000 & -0.010 & 0.000 & -0.005 & 0.000 \\
\hline Dividend yield & 16.168 & 0.000 & 2.105 & 0.614 & -1.390 & 0.401 \\
\hline Logarithm of the value of option holdings & 0.026 & 0.412 & 0.004 & 0.904 & 0.139 & 0.000 \\
\hline Logarithm of the value of share holdings & -0.105 & 0.000 & -0.064 & 0.000 & -0.025 & 0.000 \\
\hline \multicolumn{7}{|l|}{ Panel B: Volatility is not decomposed } \\
\hline Total stock return volatility & -37.676 & 0.000 & -43.706 & 0.000 & -17.778 & 0.000 \\
\hline
\end{tabular}

